\title{
A Comparison of Intranasal and Oral Flunisolide in the Therapy of Allergic Rhinitis
}

\author{
Evidence for a Topical Effect
}

\author{
A. Kwaselow ${ }^{1}$ J. Mclean,${ }^{1}$ W. Busse,${ }^{2}$ R. Bush,${ }^{2}$ C. Reed,${ }^{3}$ W. Metzger,${ }^{4}$ \\ H. Richerson ${ }^{4}$ D. Shulan, ${ }^{4}$ J. Koshiver ${ }^{5}$ and M. Chaplin ${ }^{5}$ \\ ${ }^{1}$ University of Michigan, Ann Arbor, ${ }^{2}$ University of Wisconsin, Madison, ${ }^{3}$ Mayo Clinic, Rochester, ${ }^{4}$ University of Iowa, \\ Iowa City, and 5Syntex Research, Palo Alto, California, U.S.A.
}

\begin{abstract}
Intranasal flunisolide is an effective treatment for allergic rhinitis. Flunisolide has high bioavailability when administered to normal subjects $(50 \%$ of an intranasal dose reaches the systemic circulation) with minimal systemic effects. Bioavailability in patients with active rhinitis averages $62.4 \pm 15.7 \%$. The oral dose bioequivalent to $100 \mu \mathrm{g}$ intranasally is 500 $\mu \mathrm{g}$. To define the comparative trial and systemic effects of intranasal flunisolide in patients with active allergic rhinitis, a multicenter, randomized, double-blind, placebo-controlled study was conducted during the 1983 ragweed hayfever season. Ninety-nine patients with ragweed hayfever for $\geqslant 2$ years and positive prick skin tests to ragweed were randomly allocated to one of three treatment groups: $0=$ oral flunisolide $500 \mu \mathrm{g}$ b.i.d. and intranasal placebo b.i.d.; $\mathrm{N}=$ intranasal flunisolide $50 \mu \mathrm{g}$ per nostril b.i.d. and oral placebo b.i.d.; $\mathrm{P}=$ intranasal and oral placebo b.i.d. Treatment continued for 4 weeks. Patients kept daily symptom scores. Patients were evaluated by a blinded observer every 2 weeks and were globally evaluated at the study's end. Data were analyzed for each center and pooled. There were no significant differences in symptom severity of sneezing, nasal congestion, and throat itch in the 0 (oral flunisolide) and $\mathrm{P}$ (placebo) groups. $\mathrm{N}$ (nasal flunisolide) was significantly more effective than 0 or $P(P \leqslant 0.005)$ for each symptom for at least one 2 -week period. Global evaluation demonstrated control of overall hayfever severity for $\mathrm{N}$ (nasal flunisolide) but not for 0 (oral flunisolide). We conclude that the therapeutic efficacy of flunisolide is achieved by topical and not by systemic action.
\end{abstract}

Key words: allergic rhinitis; flunisolide

Accepted for publication 28 November 1984

Intranasally administered corticosteroids are now recognized as effective agents in the therapy of allergic rhinitis $(3,4,5,7,10,11)$ yet little data is available concerning the relative contribution of topical versus systemic drug effects in the relief of symptomatology.

In 1966, Norman et al. (6) compared the effects of $1 \mathrm{mg}$ dexamethasone applied to the nasal mucosa with the oral dosage which provided the equivalent systemic effects $(0.3 \mathrm{mg})$ as measured by adrenal suppression. The data indicated that the topical route was superior to the oral drug. In the aforementioned dosages, however, dexamethasone was associated with adrenal suppression (1) by both routes.

Since this study was completed there have been no further published reports addressing the question of systemic versus topical efficacy. With the advent of newer synthetic corticosteroids such as flunisolide, which are substantially inactivated by first pass hepatic metabolism and not associated with adrenal suppression in the recommended maximal dosages (up to $200 \mu \mathrm{g} /$ day) $(2,3,7$ ), the question of 
systemic versus topical efficacy has attracted renewed interest.

In one human study (8) it was demonstrated that the effects of topical administration of 200 $\mu \mathrm{g}$ flunisolide on total circulating eosinophils were not different from those of placebo or 1 $\mathrm{mg}$ oral prednisone. However, the oral administration of $2.5 \mathrm{mg}$ prednisone or more resulted in a significant fall in the total eosinophil count.

More recently, in a human study involving 14 patients (9), the areas under the curve of plasma flunisolide after a $100 \mu \mathrm{g}$ topical dose were quite similar and bioequivalent to a 500 $\mu \mathrm{g}$ dose administered orally.

To define the comparative clinical effects of locally applied with orally administered flunisolide in dosages providing similar plasma profiles, a comparative treatment study was conducted during the 1983 ragweed pollen season.

\section{MATERIAL AND METHODS}

Ninety-nine adult patients with clearly defined seasonal symptoms of allergic rhinitis and positive immediate whealing skin test reactions to ragweed pollen were entered into the study at four centers in cities of the upper Mid-west: Madison, Wisconsin, Rochester, Minnesota; Ann Arbor, Michigan; and Iowa City, Iowa. In each center, all patients were entered just prior to the local ragweed pollen season. Each patient, after being screened for suitability and providing informed consent, kept a daily record of the duration of nasal, pharyngeal and conjunctival symptoms and the use of chlorpheniramine (4 mg) for 1 week. At the end of the week each patient rated the severity of symptoms when present. Each then was assigned randomly to treatment with either a) flunisolide nasal spray plus oral placebo, b) oral flunisolide plus placebo nasal spray, or c) oral and nasal spray placebo. $\mathrm{Pa}$ tients were randomly assigned to treatments using a restricted randomization with a block size of six. For each consecutive group of six patients enrolled by an investigator, two patients were assigned to either the nasal, oral, or placebo treatment group. This insured that the sample size for the three groups would be ap- proximately equal. Flunisolide nasal spray consisted of the currently available $0.025 \%$ solution delivered by a hand-activated pump spray unit furnishing $25 \mu \mathrm{g}$ of drug per activation. Oral flunisolide was provided in opaque capsules containing $500 \mu \mathrm{g}$ of drug. Placebos consisted of nasal spray vehicle or capsules containing an inert powder. Patients were instructed to use two sprays in each nostril and swallow one capsule twice a day. These doses provided a total of $200 \mu \mathrm{g}$ and $1000 \mu \mathrm{g}$, respectively, of flunisolide per day in the two treatment arms. Chlorpheniramine maleate $(4 \mathrm{mg}$ ) was furnished to be used on an as needed basis.

Thereafter, each subject continued to record the duration of symptoms and extent of chlorpheniramine use on a daily basis for 4 weeks. Each participant had a clinical evaluation at the end of 2 and again at 4 weeks of treatment. At the end of the 4-week study period each subject was asked to rate the degree of symptomatic benefit achieved by comparison with severity recalled in prior years. Daily pollen counts were recorded at each participant's center. In addition, the University of Iowa group independently made smears of the nasal secretions for eosinophils at each visit.

The human research committee in each center approved the conduct of the study prior to its initiation. All materials were supplied by Syntex, Inc., Palo Alto, CA. None of the patients was receiving immunotherapy or corticosteroids.

Tests performed on the study data included the nonparametric Kruskal-Wallis test for overall treatment differences, Duncan's multiple range test for pairwise treatment comparisons, and repeated measures analysis of variance (ANOVA) for overall treatment differences and treatment by time and treatment by investigator interactions. Treatment differences were considered statistically significant at the two-tailed $P \leqslant 0.05$ level of significance.

\section{RESULTS AND DISCUSSION}

Analysis of the data obtained revealed no clinically meaningful differences in either demo- 
graphics or in prior season symptom severity among the three treatment groups arms and the four treatment centers (Table 1).

All patients entered the study just prior to high pollen counts and began a baseline period of symptom scoring and prn ingestion of chlorpheniramine. Then the double-blind study began and continued through the pollen season. Representative pollen levels obtained in Ann Arbor are displayed in Fig. 1.

Of the 99 patients entered, all but two completed the treatment phase. The two not completing did so for non-study related reasons. During the baseline observation week the patients in the three treatment groups had similar symptoms and used similar amounts of antihistamine. After the double-blind study began, the three groups had significantly different degrees of morbidity. The group treated with topically applied flunisolide had significantly shorter duration of nasal stuffiness and sneezing per day, fewer days when these symptoms lasted $2 \mathrm{~h}$ or more per day and less severity when these

Table 1

Demographics and disease history of patients analyzed

\begin{tabular}{|c|c|c|c|}
\hline & $\begin{array}{c}\text { Fluni- } \\
\text { solide } \\
\text { nasal }\end{array}$ & $\begin{array}{c}\text { Fluni } \\
\text { solide } \\
\text { oral }\end{array}$ & Placebo \\
\hline No. of subjects & 31 & 33 & 35 \\
\hline \multicolumn{4}{|l|}{ Age mean (range) } \\
\hline years & $29.4(18-44)$ & $31.0(18-52)$ & $28.9(18-50)$ \\
\hline Sex (male/female) & $16 / 15$ & $24 / 9$ & $21 / 14$ \\
\hline \multicolumn{4}{|l|}{ Initial physical exam. } \\
\hline Height (in) mean & 67.4 & 69.1 & 68.3 \\
\hline Weight (lb) mean & 153.1 & 157.6 & 153.3 \\
\hline $\begin{array}{l}\text { Blood pressure } \\
\text { (mean) }\end{array}$ & $114 / 72$ & $115 / 72$ & $112 / 72$ \\
\hline \multicolumn{4}{|c|}{ Duration of seasonal rhinitis } \\
\hline$<2$ years & 0 & 0 & 0 \\
\hline $2-5$ years & 0 & 2 & 1 \\
\hline$>5$ years & 31 & 31 & 34 \\
\hline \multicolumn{4}{|c|}{ Skin tests ( $n$ positive $/ n$ tested) } \\
\hline Ragweed & $30 / 30$ & $33 / 33$ & $35 / 35$ \\
\hline Grass & $15 / 18$ & $13 / 19$ & $17 / 19$ \\
\hline Mold & $13 / 21$ & $12 / 20$ & $17 / 24$ \\
\hline
\end{tabular}



Fig. 1. Ragweed pollen counts (grains $/ \mathrm{m}^{3}$ ) during August/ September 1983 in Ann Arbor, Michigan. Volumetric method utilizing a Burkard trap.

Study dates: 5 August 1983 through 8 August 1983 baseline; 13 August 1983 through 27 August 1983 - first 2 weeks of treatment; 27 August through 7 September 1983 last 2 weeks of treatment.

symptoms were present than did those treated with oral flunisolide or placebo. No significant differences were noted for these parameters between the latter two groups. In addition, those patients treated with flunisolide nasal spray used significantly fewer doses of chlorpheniramine during the treatment month than did the other two groups. By contrast, the nonnasal symptom "eye itch" was never significantly different among the three treatment periods. This supports the hypothesis that the therapeutic effects of intranasal flunisolide are largely local (Figs. 2-4).

In accord with these responses, the treatment evaluations recorded at the end of the doubleblind study month and the comparison with prior season experience also significantly favored the flunisolide nasal spray treatment, with no differences noted between the oral flunisolide and placebo treatment groups (Table 2).

It can also be seen in Fig. 5 that the patients receiving topical flunisolide had a decline in eosinophils in their nasal secretions during the season in contrast to those treated with placebo. A lesser decline is present in the orally treated group. However, the numbers of patients in each group are too few for meaningful statistical analysis.

Adverse effects were noted by $63 \%$ of the patients in the study. The most common was transient nasal burning and stinging immediately on application of the nasal spray. It was experienced by $47 \%$ of the flunisolide intra- 


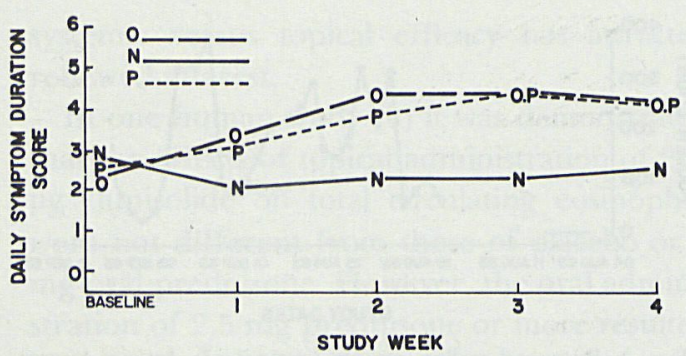

Fig. 2. Mean daily symptom duration scores. Nasal symptoms combined.

+0 - Definitely absent or questionably noted

1 - Definitely present but $<1 / 2 \mathrm{~h}$

2 -Definitely present $1 / 2 \mathrm{~h}$ to $<1 \mathrm{~h}$

3 -Definitely present $1 \mathrm{~h}$ to $<2 \mathrm{~h}$

4 -Definitely present $2 \mathrm{~h}$ to $<3 \mathrm{~h}$

5 - Definitely present $3 \mathrm{~h}$ to $<4 \mathrm{~h}$

6 -Definitely present $4 \mathrm{~h}$ or more

$\mathrm{N}=$ flunisolide nasal $\mathrm{O}=$ flunisolide oral; $\mathrm{P}=$ placebo

nasal group, $33 \%$ of the oral flunisolide group and $41 \%$ of the placebo group.

Five patients experienced mild epistaxis (one nasal flunisolide, three oral flunisolide and two placebo) and five experienced medication-related sneezing (two nasal flunisolide, one oral flunisolide and two placebo). None was severe enough to require stopping the medication or to require treatment.

\section{CONCLUSION}

Flunisolide $0.025 \%$ solution $(200 \mu \mathrm{g}$ of flunisolide/day) topically applied to nasal membranes was statistically more effective in controlling nasopharyngeal symptoms of allergic rhinitis than a systematically bioavailable dose of orally

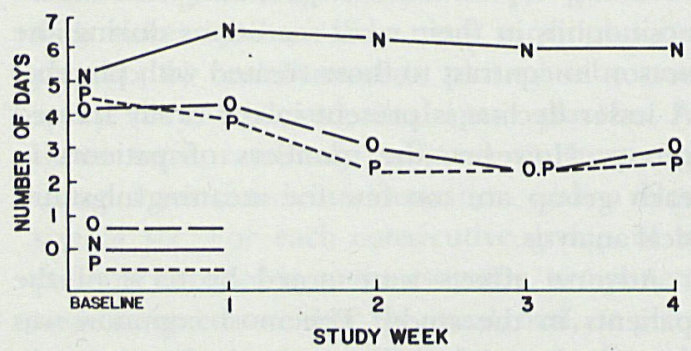

Fig. 3. Mean number of days with no antihistamine taken for nasal symptoms.

$\mathrm{N}=$ flunisolide nasal $; \mathrm{O}=$ flunisolide; $\mathrm{P}=$ placebo.



Fig. 4. Mean daily symptom duration scores. Eye itch.

+0 - Definitely absent or questionably noted

1 - Definitely present but $<1 / 2 \mathrm{~h}$

2 -Definitely present $1 / 2 \mathrm{~h}$ to $<1 \mathrm{~h}$

3 -Definitely present $1 \mathrm{~h}$ to $<2 \mathrm{~h}$

4 - Definitely present $2 \mathrm{~h}$ to $<3 \mathrm{~h}$

5 - Definitely present $3 \mathrm{~h}$ to $<4 \mathrm{~h}$

6 - Definitely present $4 \mathrm{~h}$ or more.

$\mathrm{N}=$ flunisolide nasal $; \mathrm{O}=$ flunisolide oral $; \mathrm{P}=$ placebo.

administered flunisolide (1000 $\mu \mathrm{g} /$ day) or placebo. The oral dose effects were not significantly different than placebo. It would appear that the clinical effectiveness of flunisolide

Table 2

Summary of patients' overall treatment evaluation of nasal symptoms

\begin{tabular}{|c|c|c|c|}
\hline $\begin{array}{l}\text { Treatment } \\
\text { result used } \\
\text { achieved }\end{array}$ & $\begin{array}{l}\text { Flun. } \\
\text { nasal }\end{array}$ & $\begin{array}{l}\text { Flun. } \\
\text { oral }\end{array}$ & Placebo \\
\hline \multicolumn{4}{|l|}{ Nasal symptom score: } \\
\hline Total control (1) & $5(16.7 \%)$ & $0(0.0 \%)$ & $1(2.9 \%)$ \\
\hline $\begin{array}{l}\text { Substantial but not } \\
\text { complete control (2) }\end{array}$ & $16(53.3 \%)$ & $4(12.1 \%)$ & $9(26.5 \%)$ \\
\hline $\begin{array}{l}\text { Minor, but definite } \\
\text { control ( } 3 \text { ) }\end{array}$ & $4(13.3 \%)$ & $7(21.2 \%)$ & $10(29.4 \%)$ \\
\hline $\begin{array}{l}\text { No benefit or at least } \\
\text { dubious control (4) }\end{array}$ & $5(16.7 \%)$ & $22(66.7 \%)$ & $13(38.2 \%)$ \\
\hline Aggravated (5) & $0(0.0 \%)$ & $0(0.0 \%)$ & $1(2.9 \%)$ \\
\hline Total patients & 30 & 33 & 34 \\
\hline Mean score* & 2.30 & $\underline{3.54}$ & 3.12 \\
\hline$P$-level $* *<0.0005$ & & & \\
\hline
\end{tabular}

* Duncan's Multiple Range Test - means underlined by the same solid line are not significantly different at $P=0.05$.

** Overall $P$-level is on ANOVA on ranks. 


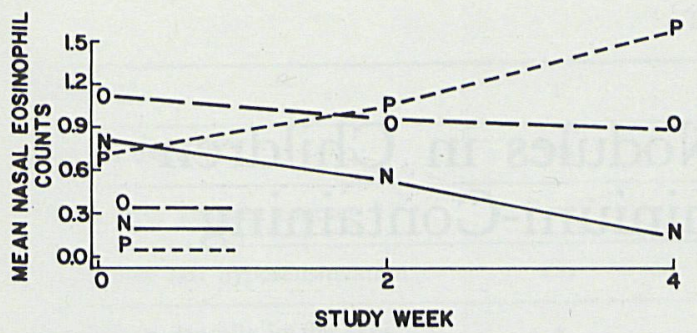

Fig. 5. Eosinophil means. Plot of mean eosinophil "counts" by study week $(n=25)$. ("Counts" refer to the scoring system noted below).

$4+=$ Large clumps of eosinophils

$3+=$ Moderate sized clumps of eosinophils

$2+=$ Occasional clumps of eosinophils

$1+=$ Occasional eosinophils

$0=$ no eosinophils.

$\mathrm{N}=$ flunisolide nasal $; \mathrm{O}=$ flunisolide oral $; \mathrm{P}=$ placebo.

nasal spray is due to its local action and not to systemic absorption. This is further confirmed by the pattern of changes in the number of eosinophils in the nasal secretions during the season.

\section{ACKNOWLEDGEMENTS}

We wish to thank Drs. Kenneth P. Mathews and William R. Solomon for editorial assistance and also Mrs. Cynthia Neubauer for secretarial support.

\section{REFERENCES}

1. Aaron T. H. \& Muttitt, E. L. C.: Effect of intranasal dexamethasone phosphate on the adrenal function of patients with perennial rhinitis. Ann. Allergy 23, 100$102,1965$.

2. Chaplin, M. D., Rooks, W., Swenson, E., Cooper, W., Nerenberg, C. \& Chu, N.: Flunisolide metabolism and dynamics of a metabolite. Clin. Pharm. Ther. 27, 402 $413,1980$.

3. Clayton, D., Kooistra, J. B., Geller, M., et al.: Short term efficacy trial and twenty four month follow-up of flunisolide nasal spray in the treatment of perennial rhinitis. I. Allergy Clin. Immunol. 67, 2-7, 1981.

4. Gale, A. E., Solomon, W. \& Tao, B. S. K.: Intranasal topical flunisolide therapy in children with seasonal allergic rhinitis. Clin. Allergy 10, 527-533, 1980.

5. Incaudo, G., Schatz, M., Yamamoto, F., Mellon, M., Crepea, S. \& Johnson, J.: Intranasal flunisolide in the treatment of perennial rhinitis. J. Allergy Clin. Immunol. 65, 41-49, 1980.

6. Norman, P. S., Winkenwerder, W., Murgatroyd, G. \& Parsons, J.: Evidence for the local action of intranasal dexamethasone aerosols in the suppression of hay fever symptoms. J. Allergy 38, 93-97, 1966.

7. Sahay, J. N., Ibrahim, N. B. N., Chatterjee, W. Y., Nassar, W. Y., Lodge, K. V. \& Jones, C. W.: Long term study of flunisolide in perennial rhinitis with special reference to nasal mucosal histology and morphology. Clin. Allergy 10, 451-458, 1980.

8. Syntex Research, ICM \# 771, 1980 - Data on file.

9. Syntex Research, ICM \# 862, 1983 - Data on file.

10. Turkeltaub, P. C., Norman, P. S., Johnson, J. D. \& Crepea, S.: Treatment of seasonal and perennial rhinitis with intranasal flunisolide. Allergy 37, 303-311, 1982.

11. Warland, A.: Evaluation of flunisolide nasal solution in the symptomatic treatment of perennial rhinitis. Allergy $37,417-420,1982$.

Address:

Dr. James A. McLean

D3257 Medical Professional Building, Box 027

University of Michigan Medical Center

Ann Arbor, Michigan 48109-0010

U.S.A. 
This document is a scanned copy of a printed document. No warranty is given about the accuracy of the copy. Users should refer to the original published version of the material. 